Cuadernos de Filología Clásica. Estudios Latinos

ISSN: 1131-9062

http://dx.doi.org/10.5209/CFCL.56188

\title{
Valerio Máximo en el pensamiento político de la Castilla medieval
}

\author{
José Luis Bermejo Cabrero; Enrique Otón Sobrino ${ }^{1}$
}

Recibido: 25 de enero de 2016 / Admitido: 20 de septiembre de 2016

Resumen. Este artículo, a manera de somera presentación y sin perjuicio de posteriores y más detalladas indagaciones, traza algunas de las líneas seguidas por la reconocida importancia de Valerio Máximo durante la Baja Edad Media Española, especialmente en los ámbitos propios, entre otros, del pensamiento político, de la justicia o de la milicia. Se basa en los testimonios hallados en diversas fuentes: obras como los Espejos de Príncipes o la Segunda partida de Alfonso X; distintos autores como Sánchez de Arévalo, García de Castrogeriz... e instituciones, por ejemplo los Consejos Aúlicos. Palabras clave: Valerio Máximo; Tradición; Pensamiento político; Administración de justicia; Literatura ejemplarizante.

\section{[en] Valerius Maximus in the political thought of the medieval Castile}

\begin{abstract}
This paper is intended to start up a research line focused on the well-known relevance of Valerius Maximus during the low Middle Ages, concerning political thought, the justice or the militia. It draws information from diverse sources: works such as the Espejos de Principes or the Segunda Partida of the king Alfonso X, authors such as Sánchez de Arévalo or García de Castrogeriz, institutions, the Consejos Aulicos, for instance.

Keywords: Valerius Maximus; Tradition; Political Thought; Administration and justice; Moralising litterature.
\end{abstract}

Cómo citar: Bermejo Cabrero, J.L. \& Otón Sobrino, E., «Valerio Máximo en el pensamiento político de la Castilla medieval», Cuad. Filol. Clásc. Estud. Lat. 37.1 (2017), 91-103.

No hará falta insistir en el hecho de que Valerio Máximo haya sido considerado como uno de los escritores más conocidos e influyentes en la Edad Media. Su nombre aparece invocado en multitud de ocasiones por toda suerte de literatos, ya sean novelistas, poetas, juristas, pensadores políticos o historiadores; y su conocida obra miscelánea servirá para hacer acopio de citas, recordar anécdotas muy diversas y ejemplarizantes o dar pie a característicos tópicos; todo ello en forma más o menos cercana al original latino.

Y así, a pesar de que se hayan escrito diversos trabajos en esta dirección, quedan muchos aspectos por dilucidar o investigar, especialmente en lo que se refiere a Castilla bajomedieval. Una Castilla donde, según se viene insistiendo ya por los

Universidad Complutense de Madrid

E-mail: deplatin@ucm.es 
estudiosos, sigue muy viva la influencia de la antigüedad y de la literatura clásica, en tanto se toma como modelo esa literatura a la hora de traducir y citar $^{2}$; y en esa misma línea surgirán modelos de conducta a la hora de exaltar acciones heroicas o comportamientos caballerescos, hasta el punto de que se haya podido hablar de un prerrenacimiento castellano ${ }^{3}$, especialmente en lo que se refiere a ciertos escritores, como en el caso del propio Juan de Mena, al decir de María Rosa Lida.

Pero la influencia valeriana cabe explicarla también desde ángulos distintos a los de la aportación clásica. La propia configuración de su obra podría explicar parte del favor dispensado por el público erudito a lo largo de distintas épocas. No hará falta recordar que se trata, en efecto, de una obra que ofrece abundante anecdotario de hechos y reflexiones sobre experiencias humanas suficientemente destacadas y características como para poder ser tomadas como ejemplo a seguir ${ }^{4}$, tanto desde el punto de vista positivo, como, por el lado contrario, a la hora de rechazar ciertas conductas descarriadas poco ejemplares; y todo ello a través de una especial consideración del ejemplo concreto como fórmula de enseñanza y acrecentamiento espiritual; algo que en Castilla no resultaba una novedad destacada, y a lo que darían pábulo asimismo diferentes fuentes de tipo oriental o que se tomaban por tales ${ }^{5}$. El caudal de datos ofrecidos por Valerio se adaptaba muy bien a tan acendrado deseo de buscar ejemplos en un pasado glorioso como el de la antigüedad, especialmente una vez convertido nuestro escritor en toda una autoridad digna de ser citada y recordada desde las más diversas instancias. Si lo había dicho o formulado Valerio, podían

2 Basamos nuestro trabajo en el examen de algunas obras que citan a Valerio Máximo desde el ángulo político, con especial incidencia en García de Castrogeriz. Quede para otra ocasión el estudio de los manuscritos medievales de la obra de Valerio, y de cuantas traducciones y adaptaciones se hicieron en la época. Para la influencia de la literatura latina en la Edad Media podemos recordar a autores como Curtius (1955) y de Ghellingck (1939, 1946). Un planteamiento aún más amplio encontramos en Jauss - Köhler (eds.) (1968-1970).

3 No entraremos aquí en el tema de si el término 'prerrenacimiento' resulta más ajustado a la realidad histórica. En cualquier caso, la afición por los clásicos en la Edad Media viene de muy atrás, a juzgar por la numerosa serie de autores manejados o citados, según ha puesto en evidencia la investigación europea. Desde el ámbito hispánico puede recordarse el capítulo «La estimación de Sócrates y de los sabios clásicos en la Edad Media española» de Maravall (1957, 275-343), a lo que podrìamos añadir una amplia lista de títulos, muchos de ellos recogidos en La tradición clásica en España (siglos XIII-XV). Bases conceptuales y bibliográficas de T. González Rolán, P. Saquero y A. López Fonseca (2000; sobre Valerio Máximo, 222-224). Como es sabido, el concepto de Renacimiento se viene aplicando a fechas tempranas. Sirvan de ejemplo los estudios recogidos por Young (1969).

4 Como es de general conocimiento, la postura adoptada por Valerio Máximo al escribir su obra histórica fue la de ir agrupando los distintos hechos narrados en secciones o apartados diferentes para dejar distribuido el material según afectara a la esfera religiosa, política, militar o, por no alargar la enumeración, al recuento de virtudes o defectos de los distintos personajes; todo ello con un claro e inequívoco propósito moralizador y ejemplarizante, con lo que su libro queda un tanto alejado de los módulos habituales de la historia narrativa para convertirse en una especie de historia miscelánea, en la que los aspectos éticos y valorativos predominan sobre la simple narración de los hechos, lo que, a su vez, produce una variada gama de niveles estilísticos y léxicos, que no siempre se deben a la impericia del escritor, sino al carácter tan particular de su obra. $C f$., en primera instancia, Rostagni (1955, 432-439), Schanz-Hosius (1959, 588-595) y Paratore (1969, 28-40 y bibliografía 465-466). Para las citas de Valerio Máximo manejamos la edición de Kempf (1885). Otra edición más moderna es la que ha corrido a cargo de John Briscoe para la Colección Teubneriana publicada en 1998. En cuanto al léxico, puede verse el trabajo de Otón (1977).

5 Como bien es sabido, la literatura de exemplos tuvo amplia repercusión en España en tantas y tantas obras: Disciplina clericalis, Bonium o Bocados de oro, Libro de los engaños, Libros de los gatos o -por no alargar los ejemplos- en buena parte de la producción de Don Juan Manuel. En semejante literatura cabe encontrar -con mayor o menor intensidad- influencias orientales de las que venimos hablando. A esta materia dedicaremos una continuación de nuestro trabajo. Desde una perspectiva europea sobre el género de los ejemplos puede verse Walter (1927). No hace falta recordar que entre nosotros hay obras cuyo carácter ejemplificatorio aparece reflejado en el propio título como en el caso del Libro de los Exemplos, en el que tanta influencia ejerce Valerio Máximo (Aragües 1977). 
quedar zanjadas cuestiones harto dificultosas. Y en ocasiones bastaba con atribuir algún dicho a Valerio para sentar doctrina. Se comprende -insistimos- fácilmente que diversas citas le fueran atribuidas sin efectiva apoyatura real; y es muy posible que circulasen textos sin pertenecerle en tanto esos textos mantuvieran una cierta conexión, aunque solo fuera formal, con su obra. Por unas y otras razones Valerio resultaría todo un personaje venerable y respetado, hasta llegar a ser considerado o valorado como un verdadero sabio, según vendría a decir el poeta Montoro $^{6}$; o bien un caballero famoso de la antigüedad muy versado en «fechos de caballería», como sucede con las Partidas $^{7}$, o que se le llegue a citar como el "grant Valerio» ${ }^{8}$ o que Juan de Mena pondere el «grant seso de Valerio», mientras algún otro autor se fija en la actividad recolectora de datos por parte del historiador latino a través de distintos lugares de la tierra, al decir de algún poeta cancioneril como Diego de Burgos (Foulché-Delbosc 1912-1915, 546): «Mira Valerio, el qual de sosiego / buscó las hazañas y hechos notables / por toda la tierra más memorables».

No faltan ocasiones en las que se confunde a nuestro autor con otros personajes históricos, ya sean antiguos o modernos. En cuanto a los antiguos el trastrueque que pueda darse en algún momento con Macrobio cabría explicarlo por la similitud de géneros literarios que ambos cultivan'. En cambio resulta más difícil explicar, entre los más modernos, la atribución que a veces se hace a Valerio del Policraticus, por muy cajón de sastre que la obra famosa de Juan de Salisbury pudiera llegar a considerarse en algunos momentos; una obra pródiga en erudición y en la que se dan cita géneros literarios bien distintos, pero que a la postre no cabe confundir naturalmente con la escrita por el historiador romano, por más que en ella se recuerde a Valerio en alguna ocasión ${ }^{10}$.

Resulta también frecuente que se atribuyan a Valerio principios de un tenor muy general con la consiguiente dificultad a la hora de localizar luego las citas. Y todo ello por el simple hecho de encajar tales puntualizaciones en la tónica general de la obra valeriana, como sucede, por ejemplo, con uno de los tópicos surgidos en torno a la codicia humana, al ser considerada, por tantos y tantos escritores, raíz de todos los males, a la manera como hiciere el Arcipreste de Talavera: «Que es asy, segund dize Valerio, que la condicia del aver es un grand emperador del mundo, al qual toda criatura servir desea» (Martínez de Toledo 1970, 258) o a la manera de las Partidas: «E sobre esto dixo Valerio el Sabio. Que el ome se deue mucho guardar de la cobdicia», iniciando de esta forma un alegato contra el vicio, sobre el que volverían las Partidas en otra ocasión, con nuevas citas de Valerio (Partidas, II, V, 14).

6 Haciendo el elogio de la reina Isabel la Católica, el poeta Montoro hablará del «sabio Valerio» (Cantera 1984, 129).

7 Pueden verse los textos de Partidas citados más adelante.

$8 \quad$ En el Decir que fiso Juan Alfonso de Baena puede leerse (Azaceta 1966, 164): «Yo ley grandes poetas

E a Tulio e a Tiberio

A Sarquel e al grant Valerio»

En el propio Cancionero aparecen equiparados, como importantes autores «Valerio, Libio e Lucano» (Azáceta, 1966: 567).

9 Tal sucede con García de Castrogeriz que atribuye a Valerio textos de las Saturnales de Macrobio, según puede comprobarse en la segunda parte de nuestro trabajo.

10 Así en el Policraticus en su libro 8, aparece citado Valerio al tratar de la compleja composición de las ciudades y del episodio del príncipe que, encarándose con la corona, hace consideraciones sobre el peso moral que entraña el ceñírsela (Migne 1841-1855, vol. 199, 771). Juan de Salisbury maneja las citas con bastante precisión. 
Otras veces la cita pretende ser cabal y exacta en tanto se alega un pasaje concreto de Valerio, a la letra o resumido en mayor o menor medida, haciendo referencia en ocasiones al libro concreto de Valerio en el que aparece recogido el pasaje. Pero, según veremos, no cabe confiar siempre en la exactitud de las citas; y aun los más fieles seguidores de Valerio suelen permitirse ciertos atrevimientos, como el citar unos pasajes por otros o refundirlos en un mismo texto. Pero los trastrueques se advierten sobre todo al manejar los nombres propios. Y, en el mejor de los casos, no es raro tomar a un plebeyo por un noble o a un romano por un 'peregrino'"1. Y lo curioso es que tales formas de aprovechar el saber polivalente de Valerio se dan a veces en un mismo escritor, donde la erudición más pretenciosa puede ir acompañada de todo un abanico de imprecisiones, lugares comunes o atribuciones gratuitas en torno a nuestro escritor.

Y es que en la Edad Media hay diferentes imágenes de Valerio más o menos fieles al 'original', aunque tal vez sin llegar aquí a producirse el conocido desdoble del autor en una especie de dos contraposiciones, la auténtica y la imaginada, como en los casos del Pseudo Aristóteles o del Pseudo Catón (Cf. Bermejo 1971). Y es que, como en tantas otras ocasiones, realidad y fantasía van aquí entremezcladas. La cita a pie de página puede ir acompañada de imaginativos devaneos en torno a nuestro personaje o de menciones incluso a textos de Valerio, hoy por hoy de no fácil comprobación ${ }^{12}$. García de Castrogeriz, que hace la glosa de Egidio Romano, con acopio erudito y profunda afición por Valerio, como iremos viendo, pudiera servir para comprobar cuanto venimos diciendo ${ }^{13}$.

Pero vayamos con los temas hacia los que se polariza 'el Valerio Máximo medieval'. Ante todo en el campo de las ideas políticas Valerio -con sus dichos ocurrentes en torno al poder y su mucho saber sobre lances e incidentes en que se vieron envueltos quienes lo ejercieron u ocuparon-debió de fascinar a otros escritores empeñados

11 Ejemplos de cuanto venimos diciendo podrán verse en la entrega posterior de nuestro trabajo, expresamente dedicado a valorar el alcance de algunas citas de Valerio.

12 Se habla en ocasiones de un Libro de los trabajos escrito por Valerio, del que no tenemos noticias: «Onde Valerio en el libro de los Trebejos dice que por ende debe ser contado el trebejo entre las buenas obras por cuanto la calentura natural se cría e se esfuerza en el cuerpo con el movimiento templado». $C f$. García de Castrogeriz (Beneyto 1947, 219) y Castigos y Documentos del rey don Sancho. (Gayangos 1952, 179).

El propio García de Castrogeriz se referirá a una epístola que envió Valerio al emperador, sin duda atribuida gratuitamente al historiador romano, ya que no tenemos otro testimonio de la relación de Valerio Máximo con el Emperador que el que se desprende de la dedicatoria de su obra a Tiberio. En cambio, sí hablará de la adulación de su amigo Sexto Pompeyo en IV, 7, ext. 2, pero tal testimonio poco se parece a la cita ofrecida por García de Castrogeriz. En este punto, conviene tener en cuenta que, como señala Huélamo $(2015,148)$ : «Hoy sabemos que los materiales que utilizó [Castrogeriz] en su glosa no eran originales, sino que los había tomado en su práctica totalidad del Communiloquium y del Breviloquium, a los que sumó textos procedentes del Moralium dogma philosophorum de Guillermo de Conches». También son de interés sobre este punto Guardiola (1985, 1989), Huélamo (1997) o Leslie (1982).

13 Abundantes citas hechas con más o menos fidelidad a Valerio por García de Castrogeriz podrán verse más adelante. En el propio autor hay, en cambio, referencias a Valerio que no encuentran correspondencia con el texto latino, según hemos podido comprobar. Tal sucede, por ejemplo, en ciertas enumeraciones sobre condiciones personales de los personajes que aparecen mencionados, como en el siguiente pasaje:

Mas aquí conviene de notar, a declaración de estas propiedades, lo que dice Valerio Máximo en el $\mathrm{VI}^{\circ}$ libro, do pone otras diez propiedades, las cuales son éstas: que el magnánimo deve guardar e acrescentar el bien de la tierra e el provecho común. Es lo primero, verdadero deseador; lo segundo, piadoso acuciador; lo tercero, afincado amador; lo cuarto, fino calador; lo quinto, de todas las otras cosas despresciador; lo sexto, de cosas gruesas e fuertes acometedor; lo séptimo, de peligros e de trabajos sufridor; lo octavo, de muerte voluntariosa rescibidor; lo noveno, de muerte de fijos e de parientes no cuidador; lo décimo, por el bien común, antes de que le dejen destruir, de la su muerte codiciador. (Beneyto Pérez 1947, 184).

Para otros temas que no encuentran - a pesar de las citas- paralelos en la obra de Valerio pueden verse ejemplos del mismo García de Castrogeriz (1.38, 313 y 2. 98, 198). 
en recomponer la imagen ideal del buen gobernante; y muy en especial, tal y como se refleja esa imagen en diversos Espejos de Príncipes. Para saber cómo el príncipe o -con más amplitud significativa el político en general- había de comportarse en tal o cual ocasión venía muy bien el recuento pormenorizado hecho por Valerio de cuantos avatares se dieron en la antigüedad en semejantes situaciones históricas, a través de una especie de visión intemporal de la vida política. Lo que fuera bueno o recomendable para el general o el senador romano podría valer o predicarse en general años después para el príncipe o el consejero áulico de turno. Si otrora se salió airoso de un dificultoso lance, parecido comportamiento podría aconsejar en épocas posteriores. Se comprende así el valor paradigmático de las reflexiones y valoraciones en torno al poder o a la práctica política ${ }^{14}$.

Reflexiones, claro está, no abstractas, sino bien concretas, sobre el talante personal que ha de reflejar el político o el caballero, las ventajas que se derivan de su recto comportamiento o los peligros que pueden surgir por no atenerse a las reglas moralmente prefiguradas. Nuestro escritor se adaptaba fácilmente al saber político de la Edad Media, donde los tópicos y los lugares comunes ocupan tan amplio espacio ya sea en escritores con acumulación de citas - desde el mencionado García de Castrogeriz al propio Diego de Valera, escritor de tan recia personalidad-, como aquellos otros que procuran dosificar su erudición, al modo de un Sánchez de Arévalo ${ }^{15}$.

Y al lado de los escritores políticos, toda una serie de literatos, que de una u otra suerte aborda el tema del comportamiento humano en sus más varias manifestaciones, hasta dar origen a todo un género de literatura centrada en el análisis de los vicios y virtudes humanas. Una vez más, saber político y moral aparecen estrictamente ligados.

Dentro de este género ocupa un lugar importante todo lo relacionado con el comportamiento femenino, uno de los temas más traídos y llevados en la Baja Edad Me-

14 Por lo general en base a supuestas citas de Valerio se recogen tópicos políticos, como el del príncipe pobre y ejemplar:

Enxemplo contra el tercer mal que pone Valerio en el libro sobredicho, do dice que los príncipes romanos mayor cuidado havían de poblar los logares e enriquescer a las cibdades que de facer a sí ricos, e más querían ser pobres que ricos porque pudiesen enriquescer a las comunidades. E pone enxemplos de muchos príncipes que tan pobres eran cuando morían que no havían donde casasen sus fijas, e los buenos varones de Roma dábanles sus casamientos muy buenos e muy onrrados. (Beneyto Pérez 1947, 38).

Otras veces se recogen tópicos en línea con cierto platonismo político, como en el siguiente pasaje del propio García de Castrogeriz:

Conviene notar que ninguno no debe saber más cosas ni mejores que el rey o el príncipe que haya sabiduría, porque ha de aprovechar a todos sus súbditos, según que dice Valerio en el VIII ${ }^{\circ}$ libro en el capítulo primero. (Beneyto Pérez 1947, 28).

15 En la Suma de la Política de Sánchez de Arévalo, obra breve y bien trabada, sin demasiados alardes eruditos, Valerio Máximo sirve de apoyatura al razonamiento político. Pensemos en lo que dice a propósito de los ideales caballerescos:

Pues deve tomar enxemplo el buen político capitán en aquel Lelio, virtuoso y famoso caballero romano -el qual militó y guerreó quarenta años sin aber sido vencido-, del qual dize Valerio que solía dezir que más confiaba en la virtud y limpieza de sus cavalleros que en las fuerças ni armas dellos. (Penna - Rubio 1959, 270).

Hay que pensar que la caballería y los ideales caballerescos se proyectan ampliamente en el saber político de la época. De ahí que el propio Sánchez de Arévalo vuelva sobre el tema, en otras ocasiones, de nuevo avalado por el historiador romano: Dezía esso mesmo qu'el cavallero dado a vicios y pecados no podía escapar de ser vencido dellos o de sus enemigos« (Penna - Rubio 1959, 270). Por su parte, Diego de Valera hará lo mismo en algunas de sus obras. Sirva de ejemplo:

Donde Valerio, en el segundo libro suyo, de Antiguas costumbres y en el tercero de Los que no parescieron en la excelencia a sus padres, pone diversos exemplos de la forma en que los cavalleros fueron penados quando contra su dever fasían (Penna - Rubio 1959, 183).

Otras citas en pp. 176, 178 y 185, con ejemplos de príncipes antiguos. 
dia. Valerio, según comprobaremos con detalle en un desarrollo posterior de nuestro trabajo, se detiene en observar a las mujeres, procurando dejarlas en buen lugar. No es que prescinda de señalar, llegada la ocasión, tal o cual defecto femenino; pero la tónica general de su obra es de alabanza, e incluso de exaltación del papel femenino, tal vez bajo la influencia de su modelo Tito Livio y de tantos escritores -Catulo, Tibulo, Propercio- que entonan encendidos cánticos de idealización femenina, hasta llegar en ocasiones a una especie de divinización. Pues bien, en la Edad Media, como es sabido, la mujer, para tantos y tantos escritores, puede resultar por el contrario cruel, libidinosa, artera, zurcidora de embustes y añagazas; todo un peligroso ejemplar humano del que habría que tomar oportunas medidas correctivas según enseñaría la historia, maestra de la vida, o la propia experiencia cotidiana -la de un arcipreste de Talavera, por ejemplo- sin que falten, naturalmente, escritores con encendidos elogios hacia el género femenino con especial insistencia en lo concerniente a su espíritu de sacrificio, al decir de don Álvaro de Luna en su Libro de las claras $y$ virtuosas mujeres o de Diego de Valera en su Tratado en defensa de las virtuosas mujeres. Todo ello, lo veremos en un trabajo independiente, aunque sin olvidar que a veces las observaciones en torno a la mujer adoptan planteamientos políticos en tanto forman parte de la familia de altos dignatarios políticos, como en el conocido tópico del recto comportamiento de la mujer del César.

Influencias valerianas se detectan también en cronistas e historiadores, especialmente en aquellos que tratan de exaltar las cualidades personales de sus biografiados, a lo que dedicaremos especial atención en un próximo trabajo ${ }^{16}$.

Por lo demás, no siempre los escritores muestran la misma predilección por las distintas partes de la colección valeriana. Sin duda el libro más conocido y mejor aprovechado es el VI, en el que se recoge abundancia de tópicos sobre las cualidades de personajes de la antigüedad suficientemente representativos.

A título de ejemplo, tras los anteriores planteamientos genéricos, nos referiremos a través de un manejo directo y a veces pormenorizado de los textos latinos y castellanos, a las relaciones estrechas que puedan darse o atisbarse entre Valerio Máximo y la literatura bajomedieval castellana. Para ello, en esta primera entrega de nuestro trabajo, nos referiremos concretamente tanto a la administración de justicia como a las experiencias surgidas en torno al mundo militar.

Sobre el comportamiento ético por razones políticas, Egidio Romano ${ }^{17}$ se vale del pasaje que hace referencia al secreto con que se guardaban las deliberaciones del Senado romano (2.2.1): adeo [...] magna caritate patriae tenebantur, ut arcana conci-

16 En las Generaciones y Semblanzas de Fernán Pérez de Guzmán encuentra Tate $(1965,286)$ influencias de Valerio Máximo. A pesar de ello, el preámbulo de las Generaciones - sin duda la principal prueba de esa influencia- resulta un tanto impreciso:

E ansí lo fallará quien las romanas estorias leyere; que ovo muchos prínçipes romanos que de sus grandes e notables fechos non demandaron premio nin galardón de riquezas salvo el renonbre e título de aquella provinçia que vençían e conquistavan, así como tres Çipiones e dos Matelos y otros muchos. (Tate 1965, 2). En efecto, en Valerio se dan algunos aspectos recogidos en la cita anterior: la integridad de los Escipiones, el desprendimiento y la probidad de ciertos políticos antiguos -no sólo romanos-. Pero todo ello resulta un tanto variado, disperso y hasta impreciso, como para demostrar sin más la influencia directa de Valerio Máximo. Por lo demás, Valerio influyó en la composición de la Compendiosa historia de Rodrigo Sánchez de Arévalo (Tate 1970, 102).

17 He aquí los textos citados:

Del cuarto mal hay enxemplo que cuenta Valerio en el primero libro, que Cornelio Scipión cuando fué enviado a Espanna a colpe que fué llegado a la hueste de los romanos, mandó e fizo pregonar que todas aquellas cosas que podían ser a delectación carnal que fuesen echadas del real, donde luego fueron echadas dende dos mil malas mugeres, porque sabía muy bien aquel sabio caudillo que las placenterías 
lia patrum conscriptorum multis saeculis nemo senator enuntiauerit; mientras relata a continuación el honestus error de Q. Fabio Máximo, para terminar de esta forma: numquam [...] taciturnitatem, optimum ac tutissimum administrandarum rerum uinculum, labafactari uolebant, que es, prácticamente, calcado por Egidio Romano: «ni querían nunca ensuciar el silencio e la puridad, que es atamiento muy firme e muy seguro de todas las cosas que se han de fazer». El pasaje 4.2.1 de Valerio Máximo es recogido por la Glosa castellana (3.17) y aparece mal citado, pues dice el texto castellano, «en el IV $\mathrm{IV}^{\mathrm{o}}$ libro el primer capítulo». En este caso, los nombres propios están también alterados, Emilio Lépido figura como Munilio Lépido y Fulvio Flaco queda convertido en Dulvio Flavio. En cuanto a la mención genérica «e eso mismo cuenta de otros» hará referencia a L. Salinator y Nerón o a Africano y Graco, etc. que en sucesivos parágrafos había citado Valerio.

El mundo de la disciplina militar dentro de amplios planteamientos políticos aparece expuesto con frecuencia en la literatura que manejamos. Entre los más representativos pasajes podemos citar por tres veces ${ }^{18}$ la Glosa castellana sobre el episodio destacado por Valerio Máximo 2.7.1, sobre el restablecimiento por Escipión de la antigua disciplina en el ejército romano durante la campaña numantina a través de tres citas concretas. La primera cita resulta sucinta y se cierra con una reflexión, que si bien se desprende del contexto, no figura en Valerio ${ }^{19}$. La segunda cita, donde aparecen mencionados «garzones e muchos omes baldíos» (en forma paralela al institorum et lixarum, junto con scorta) resulta más fiel a Valerio al tratar de la reacción del ejército que le lleva a la victoria militar. En la última cita se narra más brevemente el episodio, haciendo, no obstante, hincapié en el afianzamiento de la disciplina militar. Es digno de mencionar cómo en las dos primeras citas se conserva el número total de heteras expulsadas -dos mil, en concreto-, dato que dentro del gusto por lo anecdótico y secundario y en función de su exactitud puede servir para dar apariencia de estricto rigor histórico.

En parecida línea cabe situar la cita que ofrece Rodrigo Sánchez de Arévalo $(1959,273)$ al hacerse eco de Valerio Máximo (2.7.2): Metellus [...] omnibus imperio neruis ad reuocandam pristinae disciplinam militiae conisus est [...] sed

carnales facen al omme flaco e sin virtud e enflaquescer en todas las virtudes del cuerpo e del alma. (Beneyto Pérez 1947, 1, 34).

E desto cuenta Valerio en el $\mathrm{II}^{\mathrm{o}}$ libro, al $\mathrm{III}^{\mathrm{o}}$ capítulo, que Cornelio Scipión, príncipe romano, cuando fué enviado a conquerir a Espanna, en aquel punto que entró e llegó a la hueste, fizo pregonar que todas aquellas cosas que podrían ser a deleite de los cuerpos e a vicio de los ommes, fuesen echadas de la hueste. E entonces falló allí muchos garzones e muchos ommes baldíos e sin pro ninguno, a todos los echó de la hueste. Otrosí falló allí muchas mugeres e todas las mandó echar de su compannía, así que fueron luego echadas dende más de dos mil malas mugeres. E entonces ellos fincaron muy esforzados, ca así como antes estaban todos muy temerosos con miedo de muerte, así cobraron fuerza e corazones e tomaron consigo virtudes e acometieron a aquellos fuertes e quemaron e encendieron villas e lugares fuertes e sojuzgaron a toda Espanna, la que antes se rebelaba muy fuertemente e muy reciamente contra ellos. E aquesto fué causa que él oviese victoria por el buen regimiento e governamiento en todas sus gentes e reales, faciendo que todos fuesen muy buen apuestos e, finalmente, muy bien armados. (Beneyto Pérez 1947, 3, 311).

Onde cuenta Valerio Másimo en el $\mathrm{II}^{\circ}$ libro, al $\mathrm{II}^{\mathrm{o}}$ capítulo, que a esto tenían mientes los cabdillos más que a cosa del mundo. E pone enxemplo en Cornelio Scipion, que así como vino a la hueste, todas las malas e viles compannas que ahí falló todas las lanzó dende e los que antes estaban muy medrosos fueron después muy atrevidos e vencedores. (Beneyto Pérez 1947, 3, 342).

18 Ya hemos señalado esta tendencia a agregar consideraciones de tipo moral. Veremos más adelante un paralelismo de este tipo, más fiel a Valerio que el que actualmente consideramos, que afecta a 9. 3, ext. 4.

19 Esta tendencia dentro de la historiografía romana de índole reglamentarista puede ya advertirse a partir de la Historia Augusta. 
totam continuo in suum statum redegit: protinus, namque lixas e castris submouit cibumque coctum uenalem proponi uetuit. Por más que Sánchez de Arévalo procure abreviar, no resulta del todo fiel al original latino y en cierta manera contradice lo afirmado respecto a coctum uenalem en la fuente latina:

onde Valerio Máximo loando mucho al romano Metello dize que este capitán leyendo que en su real los caballeros demasiadamente se dauan a deleytes de manjares, defendió quen la hueste non fuesen fornos de pasteles nin se guisasen otros manjares salvo cocho e assado

La rigidez en el cumplimiento de las órdenes dadas por los mandos militares tiene su exponente más patético en Valerio (2.7.6) donde el autor proporciona el recurso retórico de la apóstrofe. Todo lo cual se mantiene en la exposición de Sánchez de Arévalo $(1959,306)$ que, en línea con la exposición valeriana, incluirá la referencia al padre: satius esse iudicans patrem forti filio quam patriam militari disciplina carere:

Otrosí, dize Valerio Maximo qu'el cónsul Póstimo Torcato estava con la hueste de Roma contra los latinios, y tenía un su fijo fuerte y animoso, el qual fue mucho rogado por algunos de la hueste que, pues tanto se allegavan los enemigos, que peleassen con ellos; y el fijo del dicho Póstimo, el padre no lo sabiendo, resistiendo, no cometiendo, travó con ellos batalla y venciólos gloriosamente. Y como viniesse victorioso con todos los despojos para atribuir la victoria a su padre, luego fue preso, y por sentencia juzgado que devía morir y ser sacrificado a los dioses; y mandólo matar. E como fuesse gran escándalo en la hueste, que tan virtuoso cavallero assí muriesse y sobre ello el padre fuesse mucho rogado, con gran costancia y virtud perseveró en la sentencia y dixo a los que rogavan: "Amigos, creet qué dolor es a mí matar a este solo fijo mío tan virtuoso y animoso; pero cosa más digna y santa es qu'el padre carezca de valiente y animoso fijo que no que la patria y república romana carezca de obediencia militar. E fueron, sin duda, palabras gloriosas, si por católico fueran dichas.

De lo qual todo se concluye que aun las grandes y graves penas que por los antiguos fueron dadas a los inobedientes, aun deven a todo ome razonable inclinar y mover a lealdad, reverencia y obediencia a su rey y príncipe.

En relación con el pensamiento político cabe situar lo referente a la administración de justicia según podemos comprobar a través de tres ejemplos significativos:

E desto cuenta Valerio muy buenos enxemplos en el VIII ${ }^{\circ}$ libro, $\mathrm{I}^{\circ}$ capítulo, do reza muchos pleitos que ovo gran piedad. El primero es que un omme mató a su hermana e el rey mandólo matar por ello, empero el pueblo, por ruego de la madre, soltólo en juicio; e el rey movió la maldad de la muerte para dar el juicio, e al pueblo inclinó razón de piedad, porque el amor que havía con su hermana castigólo más cruelmente de cuanto devía; empero prevalesció la sentencia del pueblo e el ruego que hicieron porque la madre no fincase privada de ambos los fijos. (Beneyto Pérez 1947, 3, 199).

Cabe señalar algunas alteraciones textuales en relación con el original latino, como en el caso de la intervención de la madre que no aparece explícitamente en Valerio. 


\section{El episodio de Horacio (8.1.1) es bien conocido en la tradición latina:}

M. Horatius interfectae sororis crimine a Tullo rege damnatus, ad populum prouocato iudicio absolutus est. quorum alterum atrocitas necis mouit, alterum causa flexit, quia inmaturum uirginis amorem seuere magis quam impie punitum existimabat. itaque forti punitione liberata fratris dextera tantum consanguineo quantum hostili cruore gloriae haurire potuit.

Los otros ejemplos citados aparecen en la Glosa castellana ${ }^{20}$ (8.1, Absol.1.2 y 8.1, Absol.6), que los recoge con fidelidad; en estos casos únicamente cabría precisar que en el primer ejemplo se omite el nombre del personaje que nos da a conocer Valerio Máximo: S. Galba, y lo mismo puede precisar del otro ejemplo al tratarse de L. Pisón. En cuanto al delito cometido para el autor castellano es un homicidio, lo que no parece desprenderse estrictamente de la narración valeriana: quod Lusitanorum magna interposita fide praetor in Hispania interemisset.

Sobre la crueldad de Pompeyo a la hora de administrar justicia la Glosa castella$n a$ introduce matices derivados de Valerio Máximo (6.2.8):

De la tercer magnificencia, que es en la palabra, faciendo e diciendo siempre verdad, pone enxemplo Valerio en ese mismo libro e dice que Golías, un caballero muy viejo, una vegada acusó a otro caballero que decían Liberto ante el Emperador Pompeyo. E el Emperador tomó de este enojo e comenzó a denostar al caballero viejo diciéndole: "Ahora saliste del infierno para acusar". E quiso decir que era ya muerto por vejedad e que resucitaba para acusar: E allí respondióle Golías muy afincadamente: "No mientes, Pompeyo, ca vengo del infierno e, de mientras que estuve, oí e vi que muchos se querellaban de ti que fueron a tuerto muertos e condenados de ti". E era muy fuerte cosa en aquel tiempo maldecir a Pompeyo, empero Golías por fuerte magnificencia de su corazón, díjole toda la verdad en su rostro $^{21}$ (Beneyto Pérez 1947,1,167),

La anécdota, respecto a Valerio Máximo, recibe un recorte y se pasa prácticamente a la moraleja, sin hacer referencia al catálogo de crueldades que menciona Valerio.

O sobre el castigo de los hijos por parte de los reyes. Así tenemos en la Glosa castellana (1.186), muy esquematizado el muy breve tratamiento de Valerio Máximo (5.8.1), si bien el latino ofrece las causas por las que Bruto tuvo que dar como castigo la muerte a sus hijos. Hay una referencia global a todo el capítulo. Más amplia pero

20 «Eso mismo cuenta allí de otro que fué acusado de omicidio e cuando vino la acusación ante el alcalde, el acusado no rehusó de oír la sentencia de muerte contra sí; empero comenzóse a doler cuando de unos fijos que dejaba huérfanos e él llorando rogó al alcalde que los oviese por encomendados que no peresciesen; e de que esto vio el pueblo fué mucho movido a piedad, e magüera todos havían consentido en la muerte por la gran culpa en que cayera, empero todos vinieron rogando al alcalde que oviese dél misericordia o lo perdonase, e allí la misericordia prevalesció sobre la justicia e por razón de los mozos perdonaron al padre [...] Ese mismo cuenta allí de otro que fué acusado que ficiera grandes tuertos a sus compañeros, e los alcaldes por ello comenzaren a dar muy duras sentencias contra él; e él estando allí con temor, cayó en muy fuerte enfermedad e ovo fiebre muy aguda, e con la fiebre cayó ante los pies de los alcaldes e comenzòseles a besar e besando la tierra ante sus pies finchió toda su cara e toda su boca de lodo, e esta gran omildad trastornó los corazones de los alcaldes de justicia a mansedumbre e perdonáronle» (Beneyto Pérez 1947, 3, 199-200).

21 Nótese la alteración de Liber en Liberto (tal vez originada en el libertini filius ultimae senectutis precedente) y la de Golias que sustituye al verdadero protagonista, Helvio Mancia Formiano. 
más confusa es la referencia en 2.128 de la misma obra. El catálogo que el lector tiene ante la vista:

Onde cuenta Valerio en el $\mathrm{V}^{\mathrm{o}}$ libro, capítulo $\mathrm{VIII}^{\circ}$, que muchos reyes que fueron muy buenos en castigar sus fijos. Así como Bruto de Casio e Mantilio de Aulio Fulmio, que así castigaron sus fijos que no les dieron vagar de facer lo que quisieron, más aún, cuando ficieron grandes males, matáronlos por ello.

está compuesto por Bruto, Casio, Manlio Torcuato (aquí convertido en Mantilio) y Aulo Fulvio (aquí Fulmio), padres, y no hijos, como parece desprenderse del empleo de la preposición 'de' que une a $1^{\circ} \operatorname{con} 2^{\circ}$ y $3^{\circ} \operatorname{con} 4^{\circ}$. No se hace alusión al episodio de Escauro (Valerio Máximo 5.8.4).

Y finalmente señalemos las referencias a 6.5, ext. 4 que se recogen en Castigos y documentos del rey don Sancho (Bizarri 2001, 105-106). Damos a continuación el primer texto sacado del autor castellano, pasaje que remite al relato de Valerio (6.5, ext.3) acerca de la ejemplar conducta de Zaleuco, de los locrios:

Et de cómo guardaron justicia los reyes antiguos, hay muy buenos enjiemplos. El primero es que cuenta Valerio en el cuarto libro del rey Atheneo, que establesció la cibdad de Lucrecia con muy buenas leys, entre las cuales era ordenado que cualquier home que fuese tomado en adulterio, que fuese casado, que le sacasen amos los ojos. É acaesció que un su fijo heredero cayó en este pecado, é toda la cibdad por honra del padre perdonóle la justicia, é rogó al rey su padre que gela quisiese perdonar, e él dijo que lo non faría. É tan grande fué el su afincamiento del pueblo, que lo hobo de facer condicionalmente, con una manera maravilosa, ca sacó á sí un ojo é sacó al su fijo el otro, é dejó de ver también como su fijo, é cumplió la justicia con maravilloso atemplamiento, mostrándose a un tiempo por padre misericordioso é por ponedor de la ley muy derechurero,

Conviene recordar lo que sucede con las dos distintas versiones de una obra que se asemeja a un espejo de príncipes y ofrece importante materia para nuestro tema: los Castigos y documentos de rey don Sancho, obra atribuida al rey castellano Sancho IV. La versión más antigua, de la que poseemos una edición moderna y fiable, curiosamente no ofrece citas de Valerio; sí en cambio, y con cierta profusión, las citas se multiplican en la versión posterior (Bizzarri 2001). Pero sucede que para esta versión no disponemos de una trascripción suficientemente aprovechable; hay que seguir manejando en este caso la edición de Pascual Gayangos (1952), que no se caracteriza fundamentalmente por su alta precisión ${ }^{22}$. Ante tal situación no pondremos ahora en estricta correspondencia el texto medieval con el original latino de Valerio, como venimos haciendo en otras ocasiones. Nos limitaremos, pues, a subrayar algunos de los temas tratados por la más amplia versión de los Castigos y documentos.

Como tal espejo de príncipes nos encontramos ante temas conocidos: el recto comportamiento del príncipe cristiano que cultiva las virtudes, respeta la religión, cumple con los mandamientos, y es ejemplo para los súbditos. Estos y otros prin-

22 Resulta curioso observar cómo en los Castigos se cita un tercer libro de «Policrato», como correspondiente a nuestro autor, Valerio Máximo. 
cipios animan la estructura de esta obra, acompañados esos principios de datos y ejemplos históricos en la línea que aquí hemos advertido. Lo que no significa que un autor pagano como Valerio Máximo no sea de esta forma aprovechado en el adoctrinamiento político a través de la tradicional doble vertiente de dichos y hechos. Y así al tratar de la administración de justicia sin hacer distinción de personas, además del ejemplo antes apuntado, también conviene señalar el caso del Camundio, quien aplicó esa rigurosa justicia en su propia persona a través del suicidio por no haber guardado sus propias normas. El pasaje de Valerio es el contenido en 6.5, ext., 4 y consagrado a la conducta de Carondas de Turio:

Cuenta allí otro enjiemplo del rey Camundo tirio, que puso ley para tirar las descordias de las cibdades, que cualquier que entrase en el consejo con su espada é con cuchillo, que moriese por ello. Et acaesció que á cabo de tiempo que él vino de luenga tierra á su casa, é traia su espada cinta, é así como estaba cinto entró en el consejo, é díjole un caballero que facia mal quebrantar la ley que él posiera, é él respondióle que él .compliria la ley. Et como quier que él podiera pasar desemejando este fecho ó escusándose que lo feciera por olvido, metió mano á la espada ante todos é metiósela por el vientre é matóse, é dió á sí mesmo la pena porque non feciese engaño á la justicia (Gayangos 1952, 106).

Se recuerdan también conocidos ejemplos de reyes y famosos capitanes de la Antigüedad que llegaron a derramar lágrimas cuando no pudieron ver cumplidos sus deseos de un recto y ejemplar comportamiento (Gayangos 1952, 115). Y poco después aparecen nuevas citas de Valerio sobre el empleo de la clemencia en el ámbito político. Sin olvidar naturalmente la importancia asignada a la virtud de la «largeza en el príncipe», a tenor del comportamiento ejemplar del emperador romano Tito, que no cejaba en su afán de hacer mercedes a los súbditos ${ }^{23}$.

Un tema de alcance político tratado por Valerio será el referente al no dejarse llevar los grandes dignatarios políticos de los caprichos de las mujeres ladinas, tema que tanto éxito alcanzó en el pensamiento medieval. Y en relación con el de los estragos causados por la codicia en el ámbito político más elevado se insistirá en algunas páginas de los Castigos, aunque sin entrar a fondo, a fin de no alargarse, según propia declaración del autor anónimo (Gayangos 1952, 140).

A propósito de la influencia política de la religión se utiliza también a Valerio para hacer un resumen de que el pragmático gobernante debe cultivar también virtudes que pudiéramos calificar de puramente políticas.

Con lo apuntado, sin haber agotado las citas tocantes a Valerio, queda comprobado el manejo de nuestro escritor latino por parte del anónimo de autor de los Castigos $y$ documentos en su versión más moderna lo que podría servirnos para caracterizar el amplio influjo de Valerio en fechas más cercanas al ocaso medieval.

Antes de terminar este trabajo conviene prestar atención a los distintos sectores de pensamiento de la Baja Edad Media española, según hemos tratado de comprobar.

Uno de esos sectores se corresponde con el inefable mundo de los espejos de príncipes que es donde cabe advertir con mayor intensidad la influencia de Valerio Máximo, representado en este caso principalmente por la Glosa de García de Castro-

23 Más adelante (Gayangos 1952,182) vuelve a insistir en este punto al tratar del rey Eneas. 
geriz y los Castigos y documentos del rey don Sancho en su más amplia versión. Y es natural que ello sea así dada la estructuración de tales obras en las que la acumulación de citas de carácter ejemplarizante puede servir sobremanera de guía espiritual al príncipe y, por ende, a su familia, con las virtudes morales a la cabeza, al ocupar buena parte del contenido modélico de esas obras, a veces un tanto ingenuas.

Otra corriente fácil de detectar en la época se centra en aquellas obras que toman parte de su inspiración en la línea aristotélica -principalmente a través de la Política-donde cabe siempre hacer un hueco para insertar ejemplos valerianos. En tal sentido cabe citar las obras de Sánchez de Arévalo.

Y, en fin, cabe hacer un apartado con aquellos escritores áulicos que logran alcanzar un reconocido prestigio intelectual al dirigirse a los reyes para mostrar sus consejos o sus puntos de vista a la hora de la interpretación política. De ejemplo puede servirnos Diego de Valera que a su labor teórica añade su actividad política de la mano de nuestro Valerio Máximo a la hora de elegir ejemplos significativos de la antigüedad. Es lo que hemos tratado de hacer ver sobre estas tres fases tal como se exponen en el pensamiento político bajomedieval.

\section{Referencias bibliográficas}

Aragües Aldaz, J. (1997), «Sobre las fuentes del Libro de los exemplos por abc: el caso de Valerio Máximo», en Lucía Megías, J.M.(ed.), Actas del VI Congreso Internacional de la Asociación Hispánica de Literatura Medieval (Alcalá de Henares, 1995), vol 1, 169-182.

Azáceta J.M. (ed.), (1966), Cancionero de Juan Alfonso de Baena, Madrid, CSIC.

Beneyto Pérez, J. (ed.), (1947), García de Castrogeriz, J., Glosa castellana al Regimiento de Príncipes de Egidio Romano, 3 vols., edición, estudio preliminar y notas, Madrid, Instituto de Estudios Políticos.

Berges, W. (1938), Die Fürstenspiegel des hohen und späten Mittelalters, Leipzig, Karl W. Hiersemann.

Bermejo Cabrero, J.L. (1971), «El Pseudo-Aristóteles en el pensamiento político español», Revista de Estudios Políticos 179, 85-101.

Bermejo Cabrero, J.L. (1989), Estudios de historia del derecho y de las instituciones, Universidad de Alcalá de Henares.

Bizzarri, H.O. (1997), «La estructura de Castigos e documentos del rey don Sancho IV. Apuntes para la historia de la formación de la ciencia política en la Castilla del siglo XIII», Incipit 17, 83-138.

Bizzarri, H.O. (2001), Castigos del rey don Sancho IV, Madrid, Editorial Iberoamericana.

Cantera Burgos, F. - Carrete Larrondo, C. (1984), Antón de Montoro, Cancionero, Madrid, Editora Nacional.

Cotarelo, E. (1900), Cancionero de Antón de Montoro, Madrid, Imprenta de José Perales y Martínez.

Curtius, E.R. (1955), Literatura europea y Edad Media latina. México, F.C.E.

Foulché-Delbosc, R. (1906), «Les Castigos e documentos de Sancho IV», Revue Hispanique $15,340-371$.

Foulché-Delbosc, R. (1912-1915), Cancionero castellano del siglo XV, 2 vols., Madrid, Baillo-Bailliére. 
Gayangos, P. de (1952), Escritores en prosa anteriores al siglo XV, Madrid, Atlas.

Ghellinck, J. de (1939), Litterature latine au Moyen Âge, París, Georg Olms Verlag.

Guardiola Alcover, C. (1985), «La influencia de Juan de Gales en España», Antonianum 60, 99-119.

Guardiola Alcover, C. (1989), «Juan de Gales, Cataluña y Eiximensis», Antonianum 64, 329365.

Huélamo San José, A.M. (1997), «El Communiloquium de Juan de Gales en las letras castellanas», en Lucía Mejías, J.M. (coord.), Actas del VI Congreso Internacional de la Asociación Hispánica de Literatura Medieval (Alcalá de Henares, 1995), Universidad de Alcalá de Henares, 821-828.

Huélamo San José, A.M. (2015), El Libro del governador $o$ Suma de collaciones o de ayuntamientos: versión castellana del Communiloquium de Juan de Gales, Universidad Complutense de Madrid.

Jauss, H.R. - Köhler, E. (1968-1970), Grundiss der romanischen Litteraturen des Mittelalters, Heidelberg, Carl Winter Universitätverlag.

Kempf, C. (1885), Factorum et dictorum memorabilium libri nouem, Leipzig, Teubner.

Lacarra, M.J. (1996), «Los exempla en los Castigos de Sanchos IV: Divergencias en la transmisión manuscrita», en Alvar, C. - Lucía, J.M. (eds.), La literatura en la época de Sancho $I V$. Universidad de Alcalá de Henares, 201-212.

Leslie, R. (1982), «La obra de Juan de Gales en España», en Bustos Tovar, E. de (ed.), Actas del IV Congreso Internacional de Hispanistas, II, Universidad de Salamanca, 109-116.

Lida de Malkiel, M.R. (1950), Juan de Mena, poeta del prerrenacimiento español. México, Centro de Estudios Lingüisticos Literarios.

Maravall, J.A. (1957), «La estimación de Sócrates y de los sabios clásicos en la Edad Media española», en Estudios de Historia del Pensamiento Español, Madrid, Agencia Española de Cooperación Internacional, 275-343.

Martínez de Toledo, A. (1970), Arcipreste de Talavera o Corbacho, Madrid, Castalia.

Migne, J. P. (1841-1855), Patrología latina, vol. 199, París, Imprimerie Catholique.

Otón Sobrino, E. (1977), Léxico de Valerio Máximo, Madrid, CSIC, Instituto Antonio de Nebrija.

Paratore, E. (1969), La letteratura latina dell'età imperiale, Florencia, Sansoni.

Penna, M. (1959), Prosistas castellanos del siglo XV, BAE, Madrid, Atlas.

Rostagni, A. (1955), Storia della letteratura latina II., Turín, Unione Tipografica Editrice Torinese.

Rubio, F. (1960), «De regimine principum de Egidio Romano, en la literatura castellana de la Edad Media», Ciudad de Dios 173, 32-72.

Schanz, M. - Hosius, C. (1959): Geschichte der römischen Literatur, II, Munich, Beck.

Tate, R.B. (1965), F. Pérez de Guzmán. Generaciones y Semblanzas, Londres, Tamesis.

Tate, R.B. (1970), Ensayos sobre la historiografia peninsular del siglo XV, Madrid, Gredos.

Young, C.R. (1969), The Twelfth-Century Renaissance. European problem studies, Nueva York, Holt, Rinehart and Winston.

Walter, J.Th. (1927), L'Exemplum dans la literature religieuse et didactique du Moyen Age, París- Toulouse, Librairie Occitania-Guitard. 